\title{
A Philosophical Thinking on Comprehensive Deepening Reform
}

\author{
Bin Yang \\ School of Marxism, Northeastern University, Shenyang, China \\ Email: lengshuiju@163.com
}

Received 20 April 2016; accepted 2 July 2016; published 5 July 2016

Copyright @ 2016 by author and Scientific Research Publishing Inc.

This work is licensed under the Creative Commons Attribution International License (CC BY).

http://creativecommons.org/licenses/by/4.0/

(c) (i)

\begin{abstract}
Development is the key point to solve all problems in China; however, development must be achieved with comprehensive deepening reform. By observing, thinking and studying from the aspect of philosophy, comprehensive deepening reform, which is China's temporary theoretical and practical problem, can give us a deeper cognition to the historical necessity and reinforce the initiative for this reform. This can help us to look for methods and ways to reform in scientific world outlook and scientific methodology consciously. This can also help us to gain a strong impetus to do each work.
\end{abstract}

\section{Keywords}

Comprehensive Deepening Reform, Philosophy, Thinking

\section{Introduction}

Marxist epistemology tells us that once practice develops to a certain stage and degree, new cognition and theory would appear from practice and reversely guide practice. Party secretary Xi Jinping recently has brought forward and explained the concept of "four comprehensives", which is the new thinking and new thesis based on the new historical stage of socialism with Chinese characteristics. "Four comprehensives" consists of four parts with linked logics: they are to build a comprehensive well-to-do society, to make a comprehensive deepening reform, to boost comprehensive law-based governance and to make a comprehensive self-disciplined Party, in which the comprehensive deepening reform is the basic force. Why comprehensive deepening reform is a must? How to get the driving source from it and strive us to do each work well? These questions should be answered on nation's economic development by Marxist concept from the perspective of philosophy.

\section{Dialectical Materialist World Outlook Exhibits the Historical Inevitability of Comprehensive Deepening Reform}

During the first group study of the Political Bureau of the Central Committee, Party secretary Xi Jinping pointed 
out that dialectical materialist was the world outlook and methodology for Party members, we should unite and lead people to reinforce “four comprehensives", achieve "two centenary goals", realize China dream of great rejuvenation; we must absorb the wisdom of Marxist philosophy, insist on dialectical materialist world outlook and methodology, strengthen our dialectical thinking and strategic thinking, and make all effort to improve our ability to solve the basic problems of reform and development. Now, for comprehensive deepening reform, we have two cognitive problems to solve urgently: one is why comprehensive deepening reform is a must; the other is after 37 years' reform, how today's reform can be on the correct track without being influenced by various cognitions and thinkings. Obviously, these two questions can't be answered beyond the guide of Marxist world outlook and methodology.

Firstly, a basic requisite is the dialectical materialist world outlook and methodology which is narrated as the world is united by material, material decides consciousness, everything proceeds from reality. This requisite demands us to be objective when making policy or pushing forward any work. The key objectivity nowadays is that China is and still will be in the primary stage of socialism, which is the foundation for us to understand the present statement, to plan the future, to make policy and to push forward career, nothing can do beyond this foundation. The reason why we need the comprehensive deepening reform is that we should start from this key objectivity to further implement the ideological line of setting free mind and being realistic, during which we could study the new statement, solve the new problems, face the new challenge and grasp the new chance, then we can be led by law in doing all reforms accurately and rapidly. In the Third Plenary Session of the $18^{\text {th }}$ Central Committee of the Communist, there is The Decision of the Central Committee of the Communist Party of China on Several Important Matters of Comprehensive Deepening Reform, hereinafter referred to as Decision, which emphasized that "the comprehensive deepening reform must be footed on the maximum reality that China is in primary socialism by a long way". This "maximum reality” is “ three unchanges": the basic national conditions that China is and still will be in the primary stage of socialism didn't change, the key social contradiction that people's rising demand for material and the behindhand social production didn't change, the world status that China is the largest of developing countries didn't change. After thirty years' reform and opening, China becomes the second economic entity in the world. Undoubtedly, our general productivity and people's rich degree are not high. We need to further improve our productivity, satisfy people's demand for material and raise people's happiness index. One of the most important way is to gain new motivation and in new speed by comprehensive deepening reform. The practical experience of reform and opening proved that development and reform exist with a strong positive link. Reform of each circle and layer should be focused on development, development should be searched by idea, thinking and acting point of reform. Then we can adjust productive relations scientifically, rigorously and dynamically, thus to cater to the development of social productivity, by which the upper construction can adapt to the continuous development of economic basis. Reform and opening is an eternal thesis, which is a process underway without completion. This is not only a basic attitude of dialectical materialism, but also an inevitable requisite to the reform.

Secondly, dialectical materialism also pays much attention on the great reaction to material, which is the reason why the Party regards ideological building as the most important. As for sticking to and utilizing the dialectical materialist world outlook and methodology, on one hand, it emphasizes that all must be started from objectivity, we should strengthen our willpower and keep calm to various lures; on the other hand, we should make all efforts to bring our subjective initiative, search for rules and methods in doing all works well. The rules of development tell us that once development goes further, more views would appear with it, among which are truthful cognition of objective and fair assessments, and also some mistaken viewpoints of twist assessments. In recent years, our reform continuously develops in depth and breadth with remarkable achievements. Correspondingly, controversy of reform path and method rises. When it refers to the idea, theory and culture, there are still tremendous ideological trends overseas, such as trend of nihilism on history, trend of democratic socialism, trend of old left, trend of new left, trend of neoliberalism, trend of new Confucianism, trend of nationalism and trend of populism, etc. The common point of these trends is that they all itch to plan China's reform and make a self-ideal path and method for China's future. In this case, an urgent and strict question lies ahead: which flag to raise, which way to go, which direction and goal to path? For our Party members, it's not correct to path the old and stubborn way and also the ways of other Parties, it must be from China's actual situation and unswervingly follow the road of socialism with Chinese characteristics. Comprehensive deepening reform is a great matter of practical and theoretical. How to avoid the disturbance of various fault trends, how to keep self in complex process, how to make sure of the right direction to reform, which ask us to hold and utilize the dialectical mate- 
rialist world outlook as our thinking weapon. We won't be lost when we analyze through this outlook and methodology. Take the matter of choosing path as an example, the views hold that China should go back to the traditional pattern, Chinese economy should be put into common privatization, multi-party system should be adopted and be in general election, etc., which sound good and reasonable, but whenever the false eliminated, a common fact can be found easily that all of them deviate from China's national situation and can't solve any contradiction or problem in development. Dialectical materialist world outlook and methodology show that China is in stage of storming fortification, so comprehensive deepening reform is needed. The more difficulties, the more controversies, the harder we should stick to the rule that to set everything from practical statement. The content, procedure and speed should be decided by practical statement of reform, then to find a sound solution.

\section{Dialectical Materialism Provides a Basic Method for Comprehensive Deepening Reform}

Dialectical materialism, with profound connotation and rich extension, is the basic way to know the world. The study, understanding, grasp and utilization of dialectical materialism can enhance our ability to think, improve our skill in solving complex problems. The deeper our career develops, the more demanding to our dialectical thoughts. The complexity of comprehensive deepening reform asks us to analyze and handle problems by this methodology.

Firstly, relation and development are the general characteristics of materialistic dialectics. Engels has said: "When we inspect nature, human history and our spiritual activities by thought, we can feel pictures with kinds of relations and interaction (Mao, 1991). From the point of universality of relation, all inner parts and elements are inter-related, everything is mutual-related with others. This demands us to be good at analyzing various relations between matters, be good at analyzing and solving problems from an overall perspective. With reform's going deeper, we have gained a comprehensive and profound cognition to it. Nowadays, some people are still to be improved in cognition, especially for those government leaders. For example, some can find that market plays a decisive role in resource allocation, but they neglect the role government should play as well; some local governments have eyes only on economic growth, but they neglect ecological environment, social career and living quality, etc. In fact, if we only pay attention to market without government, we couldn't solve possible problems of monopoly, unemployment, discordant regional development and uneven distribution of wealth. Those problems will lead to some bad results like the decrease in buying power and insufficient effective demand, which would influence the market role in resource allocation. If economic growth is emphasized misleadingly beyond the attention to the development of ecology, the ecology must deteriorate. Then investment will decrease and capital will flow out, which will impede economic development. To solve these problems, we must take the view of relation, overcome the one-sidedness of thought, and accurately understand the general goal of comprehensive deepening reform and the tight relations among each target. Thus we can avoid blind decision and implement this reform.

Secondly, materialistic dialectics holds the view that contradiction is the basic motivation of development. Comprehensive deepening reform demands us to understand and handle every contradiction comprehensively. For today's reform, it's the historical stage to be "deepening reform". Then how to understand this "comprehensive"? Lenin said, "To fully know something, one must grasp and study all its aspects, all relations and "medias". We can't absolutely achieve all, but this demand can avoid our mistakes and stubbornness (Marx, K. \& Engles, F., 2009). Mao Zedong pointed out in On Contradiction that "when studying something, not to be subjective, one-sided and superficial. One-sided means can't study comprehensively...One-sided and superficial are both subjective” (Lenin, 1958). From bigger level, comprehensive deepening reform includes six aspects of economic structure, political system, culture system, community organization, ecological civilization construction and Party building. What the "comprehensive" emphasized is not only for these six aspects themselves, but also for the reform of each aspect. By studying the top-layer design of Decision, we can easily find that besides "the great significance and guiding thought of comprehensive deepening reform" in the first part, the rest 15 parts are actually footed on comprehensiveness, serve for the deep design of the general goal, which is an engine with related systems. As an instructive file of our Party, its philosophy is obvious, it showed that all things are related, interactive, interplayed and mutual effected. It embodied that comprehensive deepening reform must focus on the systematicness, integrity and cooperativity, must harmoniously boost the five constructions of economy, politics, culture, society and ecological civilization. 
Thirdly, the combined doctrines that everything has two aspects and everything has its key points are important for materialistic dialectics. On analyzing development, one must pay attention on grasping the main contradiction and its main aspect. This demands us to focus on the main points when considering and handling matters. Decision emphasized that we must stand on the maximum reality that our country is in the primary stage of socialism and for long; we must stand on the great strategic judgment that development is the key to solve all problems; economic construction is centered, economic system should play a motor role to promote the coordination between productive relations and productivity, between upper construction and economic base, to accelerate a continuous social development... thus to grasp the main points of reform. Decision has further emphasized that the core of economic system reform is to handle well the relationship between government and market, thus to grasp the main points of reform. Meanwhile, in each domain of reform, Decision grasps every key point and main line tightly. Six "closely surrounds" are put forward in Decision, which made the themes of each domain's reform clear. For instance, about constructing ecological civilization, Decision proposed that ecological civilization must be set in complete system; source protection system, compensation system and responsibility investigation system must be strictly carried out; environmental treatment and ecological recovery system must be improved, and environment must be protected by these systems.

\section{The Historical Materialism of Adhering to People's Historical Subject Position Shows the Reliable Power and Main Path of Comprehensive Deepening Reform}

Adhering to people's historical subject position is the cardinal stand for historical materialism. Marx deemed that the primary of social development history was productive development, and also the producer history, that was the cardinal stand of Marxist Party to people.

Firstly, people are the reliable power for comprehensive deepening reform. People are the inventor of history and the power resource of our Party as well. If there is no support and promotion by people, no reform can be achieved. Back to the 37 years' reform and opening, each breakthrough and development was from people's wisdom and practice. Facts proved that the reliable power of comprehensive deepening reform was to adhere to people's subject position. Decision explicitly viewed to adhere to people-oriented, respect to people's subject position, release people's inventory spirit and boost reform by people (China Daily, 2013). People are reliable in reform, which demands us to see people's satisfaction as our basic evaluation criterion. We must dynamically and seriously respond to people's livelihood, only by this, the Party and government can gain real support from people, and then each reform can be carried out. In fact, from the reform measures in Decision, we can see that economy, politics, society and culture are all included, which fully covers every domain of people's livelihood, which is closer to people's lives; the hot issues and difficulties are cared much and gained endeared and practical response, such as implementing two-child policy, reforming household registration system for removing barrier between urban and rural, reducing subjects in nationwide exam, abolishing the system of reeducation by labor, endowing peasants more proprietary right and accelerating lawmaking of housing and land law, etc. These fully explain that the grand blueprint of comprehensive deepening reform is designed by people's practice, it's extracted and purified by people's wisdom.

Secondly, the main path of comprehensive deepening reform is to release people's subjective role. During the hard time of reform, it's our historical duty to get comprehensive deepening reform attached by new trend. To further reinforce people's historical subject position and greater spur people's role, we must abide by the rule that all for the masses, all rely on the masses, all from the masses and back to the masses. We need to be close to the masses to boost the reform. The reform itself is a complicated process which is related to each domain of society, especially when it goes into a hard and deep stage; the problems it will encounter would be more intricate and thorough. How much trouble the reform will face, if we put ourselves to people's position, treat every problem from the masses' point of view, and take every maximum interest into consideration, then it can be solved easily.

\section{References}

China Daily (2013) The Decision of the Central Committee of the Communist Party of China on Several Important Matters of Comprehensive Deepening Reform.

Lenin (1958) Collected Works of Lenin, Book Thirty-Two (p. 83). Beijing: People’s Publishing House.

Mao, Z. D. (1991) Selected Works of Mao Zedong, Book One (pp. 313-314). Beijing: People’s Publishing House.

Marx, K., \& Engles, F. (2009) Collected Works of K. Marx and F. Engles, Book Nine (p. 23). Beijing: People’s Publishing House. 


\section{Submit or recommend next manuscript to SCIRP and we will provide best service for you:}

Accepting pre-submission inquiries through Email, Facebook, Linkedin, Twitter, etc A wide selection of journals (inclusive of 9 subjects, more than 200 journals)

Providing a 24-hour high-quality service

User-friendly online submission system

Fair and swift peer-review system

Efficient typesetting and proofreading procedure

Display of the result of downloads and visits, as well as the number of cited articles

Maximum dissemination of your research work

Submit your manuscript at: http://papersubmission.scirp.org/ 